\title{
Expansion and Innovation
}

Five years have passed since I have taken on the editorship of Respiration! Another year with an unbroken upward trend in the importance of the journal! What do I base this statement on? Very simply on two facts: (1) the number of submissions is still on the increase although we have implemented a very strict policy of quality which I have announced in previous editorials, and (2) the increasing number of subscriptions. Currently, $70 \%$ of all unsolicited articles are rejected, which compares with the percentage of rejections of other leading respiratory journals. The increasing number of submissions we receive allows us to stick to this policy for the future. So, dear potential contributor, do not send us any second-rate material hoping for acceptance. The days where Respiration has accepted $50 \%$ of submitted papers are a thing of the past!!! All right, you may say to yourself, we have noted the fresher wind in Respiration, but besides quality, is there anything new for the coming year we might want to hear about? Yes!

Firstly, the newly founded European Association for Bronchology and Interventional Pulmonology (EAB) has chosen Respiration as its home journal. This means that the society now 'owns' the dedicated section of Interventional Pulmonology for their publications (articles, an-

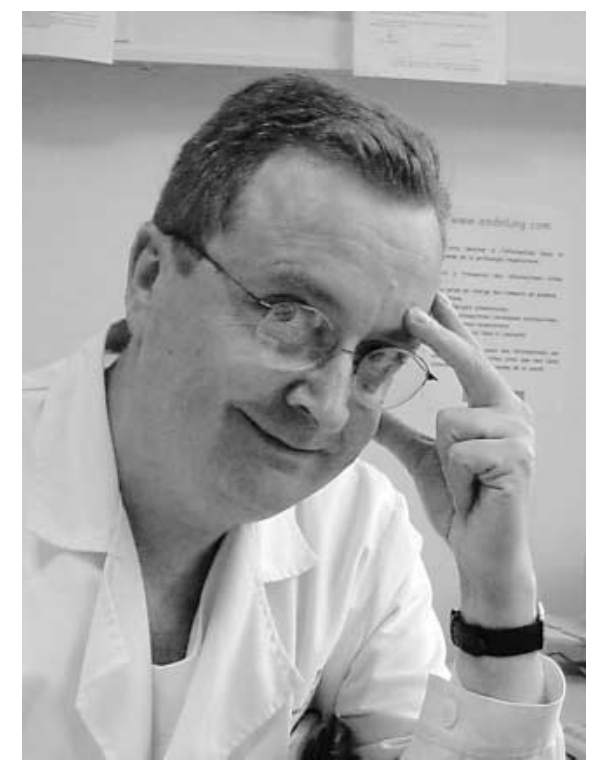

Professor Charles-Hugo Marquette, Lille.

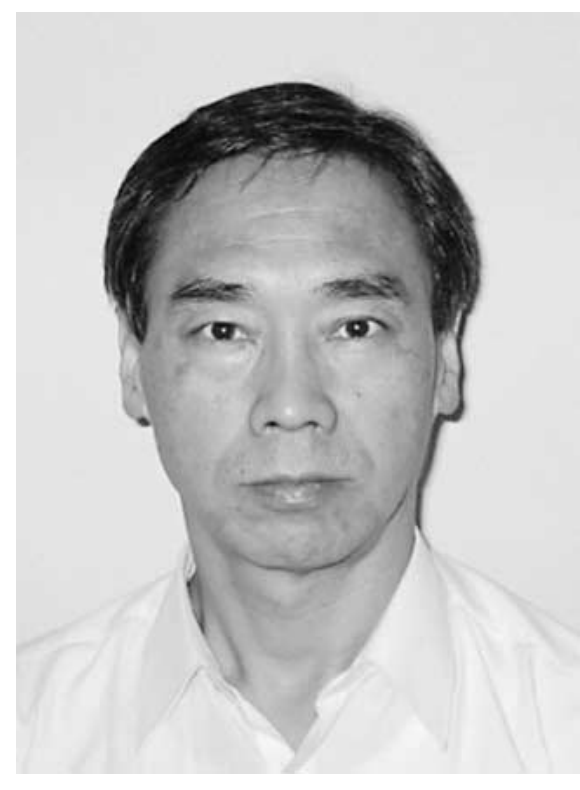

Professor Takashi Nishino, Chiba.

\section{KARGER}

Fax + 41613061234

E-Mail karger@karger.ch

www. karger.com
(C) 2003 S. Karger AG, Basel

0025-7931/03/0701-0001\$19.50/0

Accessible online at: www. karger.com/res 
nouncements, discussions). Again, as a reminder, the same strict quality criteria will apply as for the rest of the journal. As I indicated previously, the ultimate decision of acceptance for papers in all sections remains with the Editor-in-Chief. This 'marriage' of an established journal with a new society will profit both sides equally. The EAB has an established home which is indexed everywhere, so the articles are citable with immediate effect! Respiration, which so far has not represented a society, will get an increased readership, as membership to the society and Respiration are linked (see also the following editorial by Professor Becker, EAB president).

The overall scope of Respiration, however, will remain unchanged: a journal for all aspects of thoracic medicine! All the existing sections will continue, EAB is just a further enrichment.

A second important innovation for 2003 is the move to electronic manuscript handling. While a number of other journals have already implemented this recently, S. Karger AG prudently waited to see how the different software packages compared. Finally, a choice has been made, and XpressTrack, the new online submission and peer-review system, is currently being installed. The system looks very user friendly, and Respiration will be one of the first Karger journals to use it as of this year.

Initially, both electronic and paper versions will be accepted during a transition phase of 1 year, after which only electronic submissions will be possible.

Finally, it gives me great pleasure to announce two new members in the team of associate editors: Professor Charles-Hugo Marquette, Lille, France, and Professor Takashi Nishino, Chiba, Japan will join Respiration as of the beginning of this year. Professor Nishino takes over from Dr. David Paterson, whom we would like to thank for his outstanding term as associate editor for the Basic Science Section.

Dear reader, the unbroken and increasing support from contributors, the new society, and the switch to electronic communication will guarantee the continued and increasing success of Respiration in 2003. Last but not least, I would again like to thank all Associate Editors and Board Members for their continued enthusiasm and adherence to quality in their judgments, and the people around Linda Haas at the Editorial Office in Basel for their outstanding performance!

C.T. Bolliger, Cape Town 